\title{
The Cinema and Real Time
}

\author{
By Jacob Potempski \\ Spring 2012 Issue of KINEMA
THE CINEMA AND REAL TIME: AN INVESTIGATION OF THE MEDIUM'S RELATION TO TIME

Christian Marclay's deranged clock

CHRISTIAN Marclay's The Clock (2010), the film that won the Golden Lion at this year's Venice Biennale and was quickly snapped up by a number of major galleries (including MOMA and the National Gallery of Canada) is literally a clock, or a perfect simulacra of one. Having found a clip for every minute of the day, Marclay spliced them together to form the moving-image of a 24-hour clock, which, as if to make the likeness complete, is projected in real-time. The discovery that there is an image for every minute of the day serves as a reminder that the cinema has always been concerned if not obsessed with time. However, the concern has not always been with real-time. One could even say that the cinema has always presented us with the opposite; with invented, imaginary time, which makes us oblivious to the realities of the day. But the escape from the present - The Clock reminds us - is never complete. Real-time goes on; passing along with the time of the film. The question, which the film raises, is: what is the relation between these two times, the cinematic and the real? To put it differently, is real-time the universal that unifies all of the times invented by the cinema; or does each film, even The Clock, beat to its own measure?

On first impression, the film not only gives us an identical representation of real-time, but constantly serves to remind us of its presence. Functioning as a commentary on the cinema, it seems to say that no matter how hard they try, the movies will never make us oblivious to the present and to all the anxieties that are wrapped up with it. Considered more metaphysically, The Clock seems to argue that real-time is reality itself; the light, as it were, behind the play of shadows; which the cinema serves as its master. This is how a number of commentators have seen the film. For example, in his Artforum February 2011 review ("Borrowed Time") David Velasco wrote that the film serves as a reminder "that every camera, every image, can be put in service of the real."

But what is real-time? It is the common sense of time that organizes much of our daily experience. We often take it for granted, forgetting that it is a certain representation of time and not necessarily an objective state of affairs. However, modern philosophers, beginning with Henri Bergson, have argued that real-time is simply a frame through which we measure time, the true nature of which is in fact immeasurable. Bergson argues that when we measure time we treat it as though it were space. Events that are in fact perpetually in flux are reduced to the level of objects with determinable dimensions, as though they were fixed and unmoving. ${ }^{(1)}$ The frame of measure, for example the $24 \mathrm{~h}$ clock (the minute or the hour), serves as a common denominator by which a variety of events, irrespective of their differences, can be referred to an objective point of reference.

Time is thereby represented as the movement of one and the same now, which itself never changes. The movement is, moreover, represented as a chronological succession: the present comes first, the past functions as a copy; which is, in turn, reproduced in the present (much like the order of cause and effect). Bergson does not deny that this way of representing time is very logical and useful. By establishing correspondences between different moments, we are able to predict and control the outcomes of various processes. However, he argues that time is more creative, and that by virtue of this creativity each moment is different; radically different, such that it cannot be represented in terms of a common measure. It is this creativity of time that, Bergson suggests, comes to the fore in works of art.

In order to get a better sense of creative time, let us consider the relation between past and present, which, I will argue, forms the crux of The Clock, from a Bergsonian point of view. In contrast to the objective representation of time, Bergson emphasizes the heterogeneity of each moment. No matter how much the past might resemble the present, it cannot be reproduced. This is a simple fact, but we do not take account of it in our customary representations of time. However, the difference between past and present, from a Bergsonian point of view, is not a simple juxtaposition. We cannot, for example, divide the different moments of our 
lives as neatly as one might divide a cake into equal separate pieces. The past as a whole inheres in each of our present acts. The things that we have lived through are expressed in these acts.

Conversely, the present is not the instant, with clearly determinable boundaries, which we isolate in order to measure. It is submerged or plunges into the past at the very moment that it becomes present. In other words, rather than a chronological succession of discrete instants, for Bergson time is a continuous flux, wherein moments flow and melt into one another, each one transforming and being transformed in relation to the other. In this sense time is not only composed of differences, it perpetually differentiates, that is, makes anew, past and present simultaneously. Bergson often used the example of a melody, where we retain the preceding parts as the new ones arrive, and experience each part modifying the other. ${ }^{(2)}$ He was, however, more sceptical about the art of cinema. He argued that the cinema can only give us an artificial image of time, a mechanically produced homogeneous time. ${ }^{(3)}$

The first impression of The Clock, which, as I mentioned, many viewers are left with, would seem to confirm this claim: not only is the film itself in real (objective) time; also, functioning as a meta-commentary on the cinema, on the cinema's relation to time, it suggests that every film beats to this measure. However, the work of Gilles Deleuze has shown that the cinema is more than capable of creating creative times, times that open past and present towards the future, in Bergson's sense of the word; despite what Bergson had to say about it. ${ }^{(4)}$ Does The Clock confirm this Deleuzian hypothesis; that is, does it make visible differences in time, the difference that the cinema makes in time; or does it, rather, project the cinema as a homogeneous medium, which reduces every moment to a common measure? It seems to me that when we assimilate the time of the film to real-time, the image (past) to the real (present), we miss the play of difference that really makes Marclay's film tick.

In the history of writing on film not much is to be found regarding the relation between the cinema and real-time. However, in The World Viewed, Stanley Cavell reflects on the change that takes place between the time registered on film (the reality of the world viewed) and the present time of the projection (the viewer's real-time). ${ }^{(5)}$ These reflections can help us think about The Clock in relation to the question of time and the cinema. Cavell writes: "What does the silver screen screen? It screens me from the world it holds - that is, makes me invisible. And it screens that world from me - that is, screens its existence from me" (24).

The cinema makes present a world that is absent. It makes it present to a viewer that remains absent from it. Cavell understands this relation between absence and presence in terms of time; adding, "and a world I know, and see, but to which I am nevertheless not present (through no fault of my subjectivity), is a world past" (23). The barrier of the screen functions, from this point of view, as a line dividing the time of the film, the world of the film that took place in that time, and the present from whence the viewer peers out. ${ }^{(6)}$ "That the projected world does not exist (now) is its only difference from reality" (24). This minor difference of time, while being unbridgeable, is almost imperceptible, so deeply interfused are the two registers of the screen.

There is a difference, in other words, between the time that is passing in a film, the present of the world viewed, which is past in relation to the present of the viewer, and this present; that is, the present in which that past present is now passing. This is an ontological claim, which implies that every cinematographic image is past, a past projected in the present. No matter what the representations of time, which could refer to a future time, or to the present time of the viewer (as in films where characters address themselves directly to the audience, aiming thereby to break down the barrier of the screen) the image retains the ineluctable mark of the past, of a time that is no longer, and that is made present as such.

This is why, in the cinema the barrier (unlike the "fourth wall" of the theatre) can never be broken down. The world viewed is always sealed, or, to use Cavell's word, screened from that of the viewer. Marclay has not achieved the impossible perfect coincidence of these two times, these two worlds. He has, however, complicated and played with the difference; exploiting the fact that it joins what it separates (past and present, the image and the real), in order to produce a certain derangement of time.

In The Clock the difference is between the past time registered by each image of the film and the present time of the viewer; that is, the distinctive mark that separates each image comes strikingly into view, upon a closer look. The film is a moving spectacle of time-pieces of the most diverse kind. Each time-piece marks 
the present time of the narrative as well as the real-time of day, as though they were one. But the images are marked historically. Not only the grandfather clocks, even the wrist watch, the leather-strap variety (for example, on the hand of Sean Connery as James Bond) will appear retro for the young viewer, who is likely to check his cell phone for the "corresponding" time...

The mark of history is also revealed by the fashions and styles of filmmaking, which distinguish the images from one another. The spectacle of time-pieces therefore also functions as a spectacle of the history of the cinema; wherein one and the same theme, time, appears in innumerable variations. Projecting these images in sync with the present effectively allows their datedness to come to the fore. Difference stands out through the contrast.

However, The Clock is doubly dated. For it is also dated as present, a present projection of the past, in reference to real-time. The film is not simply defined by the archival material that it samples. It appropriates images past and makes a new present out of them; each one serving as a part, a minute or less, of a new 24-hour cycle. Every image is thus present and past "at the same time." But the coincidence is established between heterogeneous times.

The two registers of time appear as identical only if we ignore the historical markers that distinguish the images from one another and from the present of the viewer; that is, if we reduce the film to the empty frame of real-time. In fact, the coincidence - of, for example, 4:55pm marked by a Lubitsch film and 4:55pm in Vienna - serves to confuse the coherence of both registers, as it brings them together while holding them apart. The two times, the real and the cinematic, past and present; in Cavell's words the time that is screened and that from which it is screened; remain distinct while becoming indiscernible. Precisely where and when we would expect to find a perfectly symmetrical identity, that is, in the present of The Clock, there is a disorienting play of difference, which sees the real and the cinematic pass into one another and perpetually exchange places.

The disorientation takes place not only between each image and its real-time referent, but also between the film as a whole, that is, the 24-hour sequence of the film, and the corresponding 24-hour real-time sequence. In this regard as well the film only seems to move in line with the chronology of real-time. But considering the historical markers of the images, the film is oblivious to chronology. For example, at around 7:00 am a Rube Goldberg machine wakes up Michael J. Fox (Marty McFly) from Back to the Future, made in 1985; and then a naked JoBeth Williams jumps out of bed after a one-night stand with Dustin Hoffman, screaming as she runs into a young boy in the hallway, from Kramer vs Kramer, made in 1979.

What came before, in the order of history, comes after, in the order of real-time (the order of the present projection). The film takes the greatest liberties in leaping back and forward in time. However, what holds this crazy montage together, and what gives the film its proper rhythm, is the fact that it coincides with the sequence of the real. The chronological order is constituted at the same time that it is unravelled. Time is reversed while it marches on. There are effectively two clocks, a virtual and a real, nested within or superimposed upon one another. Each serves to displace and to confuse the identity of the other, by virtue of their coincidence.

Perhaps the most remarkable thing about the film is the fluidity that Marclay achieves in moving from one disparate image to another, creating the illusion that all of these moments are going on in one continuous time, which contributes greatly to the sense that the assembled film is taking place in real-time. We move across different periods of the cinema as characters move across the threshold of a doorway, entering the door in a film from one period and existing in another. The screen is also cleverly used to this effect, which makes for a self-reflexive gesture, reminding us that what is at stake is the time of the medium.

For example, sometime approaching midnight, handsome Frank and Louise (from Ghost Dog) are drinking wine and watching cartoons; Frank turns the channel and the film turns as well, to a different film, a different apartment with a different TV, where someone has just turned the channel; a few "channels" later, Hitchcock is on TV, telling us that "the hourglass is a wonderful invention..." The soundtrack also provides an important thread ("the acoustic glue," as Marclay, originally a turntablist, called it). ${ }^{(7)}$ Sounds continuing from one scene to another, sounds overlaid across various clips, sounds or musical pieces (for example, Mozart's Requiem plays across scenes from the afternoon, Mahler's Resurrection Symphony across 
those of midmorning) make for incredibly smooth transitions. Establishing continuity, creating a new and seemingly real temporal order, out of images taken at different times, is simply how movies are made. The montage that creates a film's time usually takes certain liberties with regard to real-time (through ellipsis, for example).

The Clock, on the other hand, seems to be strictly determined to keep time with real-time, aligning the flow of the images with the movement of the dial. The irony is that it is in fact a montage of false continuities. Through the seemingly seamless transitions the seams show through; as none of the images fit, logically, one next to the other. There is perhaps no more irrational film, no film so strictly committed to irrational cuts, and indifferent to coherent narrative transitions. The Clock flows, in other words, but it flows against the grain of real-time.

The Clock exploits and does not simply level the difference that joins while separating the time of the viewer to that of the screen. The dis-junction, which affects both times, transforming and destabilizing the one in relation the other, takes place in two correlative ways: between the past time retained by each image and its real-time referent, on the one hand; and between the irrational 24 hour sequence of the film and the real 24 hour sequence, on the other. The time that is thereby produced, produced, that is, by putting the medium into relation with real-time in this way - the double or duplicitous time of The Clock is neither real-time nor the hermetically sealed time of the film. It is a heterogeneous time, in the sense that it differs within itself, perpetually (and imperceptibly) passing from one register to the other. Its identity, that is, the "coincidence" of its two sides, is thus constituted as an identity of difference. To put it differently, the time of the film is that of an otherness that is other to itself.

I began with referencing Bergson's distinction between real-time and our more creative experience of time. Creative time is an ever-changing process, a process wherein each moment changes in relation to every other. Real-time, on the other hand, is time understood as a series of discrete nows; which is to say, as a series of points of rest. While The Clock does not give us an experience of duration in the way that Michael Snow's Wavelength or the slow sequence shots of Ozu may; it nonetheless establishes a series of relationships between past and present, before and after, which serve to derange chronology and constitute a time of perpetual transformation.

The two times, creative and real-time, coexist. Marclay's derangement of time does not simply negate realtime (how could it?). The deranged time takes place along side or along with real-time. That is to say, in between one minute and the next, in between the present and the former present, the film opens up a different register of time, which is heterogeneous. One can always reduce the film, every film, to real-time, by simply clocking the sequence of images. But one thereby misses the creative work of the cinema; that is, the time that is formed by the image and the relations between images; which is never reducible to real-time, even in the case of a film that looks very much like a clock.

As I mentioned at the beginning, the idea that the cinema creates its own creative time, in Bergson's sense of the word, is introduced by Gilles Deleuze. Deleuze valorizes the cinema's capacity to actualize a virtual register of time. The virtual time of the cinema is never in the (real) present. Dividing in both directions at once, it constitutes a "state" of perpetual renewal or limitless transformation. ${ }^{(8)}$ However, the examples that Deleuze gives of this cinematic accomplishment almost always refer to the functions of the narrative (for example, the status of the character within the context of the story). The Clock, on the other hand, actualizes creative, heterogeneous time by mobilizing functions which are specific to the cinema alone: the archive, or the memory of the image, which retains the mark of the past; and projection, which brings the archive to life in the present. That is to say, it exploits the gap between the time registered and the time projected - a gap that lies at the heart of the cinematographic apparatus - to create a two-sided clock, which simultaneously recalls the past and makes it present anew.

Contrary to first impressions then, The Clock is nothing like a real clock. It does not repeat the same movement, the same Now, ad infinitum. If we see the film as a meta-commentary on the cinema as a whole, which it invites to do, it does not suggest that the cinema is in service of the real. Rather, projecting the difference that the cinema makes in time, it suggests that the cinema never simply keeps time; but always makes its own time by dis-organizing real-time. Each film is a clock, in other words, but essentially an idiosyncratic one. 


\section{Dan Graham's Present Continuous Past(s)}

The Clock is one of a kind. If it does, however, have a precursor, it is not to be found among cinematic real-time experiments, like Andy Warhol's Empire. ${ }^{(9)}$ Rather, it is to be found in works that explore the relation between (to use Cavell's language again) the time that is screened and the real-time from which it is screened. This is the modus operandi of Dan Graham's Present Continuous Past(s), a 1974 video installation. The work also seems to reflect the real-time of the viewer. More specifically, it seems to reflect (literally, like a mirror) the unified subject, the subject that remains present to itself across time, which is pre-supposed with the homogeneous concept of time, as the correlate of the objective present. But in fact, like The Clock, Graham's work displaces the present, by bringing it into relation with the past registered on the screen. As a result the unity of the subject comes undone. Although it is a video-installation, and some would argue, a performance piece, I will argue that the work constitutes a great example of the cinema as a machine for the creative dislocation of time, and of the certainties that hinge upon it.

In the work the viewer finds herself in front of a camera and a monitor: a camera that records her, and a monitor that projects her image eight seconds later. ${ }^{(10)}$ The key to the effect of the work is that the interval is just short enough to imply a sense of continuity, of the present with the past, and yet just long enough to mark the difference. By virtue of this duplicity, the interval separates the past retained by the image from the present of the viewer, or the image of the viewer from the viewer present before the screen; yet it joins them at the same time. The past is thus made contemporaneous with the (viewer) present, appearing as its mirror reflection. But it is a heterogeneous past, a sort of counterfeit double, that replays the viewer in the role of an other - an other within.

The notion of a past contemporaneous with the present recalls Henri Bergson's analyses of memory, and their application to the cinema by Deleuze. It is these analyses that are invoked by Elie During in his reading of Graham's work. ${ }^{(11)}$ Bergson argued that memory is not formed after perception. It is formed contemporaneously with the creation of perception ("au fur et à mesure...") like a shadow alongside the body; even if consciousness is not aware of it normally, "just as we should be unconscious of our shadow were our eyes to throw light on it each time they turn in that direction."(12) Bergson is led to this claim from his initial insight into the fluid nature of time; that is, past and present are contemporaneous insofar as time does not move in "fits and starts," from one point of rest to another, but flows, such that each moment ("melting," the one into the other) is already past and still to come. Now, insofar as it is contemporaneous with the formation of perception, memory never fails to produce a disconcerting effect of déjà-vu.

That is to say, if the present has already past (has past as soon as it became present) it is always (always and already) the effect of repetition. While perception, the perception of the present, gives the subject the sense of actively and freely engaging with the world, the co-presence of memory makes that very activity seem like the acting out of a role, a simulacra. The subject is thus divided between past and present, its consciousness split between memory and perception: "Thence two different selves, one of which, conscious of its liberty, erects itself into an independent spectator of a scene which the other seems to be playing in a mechanical way" (149). This description applies even more readily to the experience of the video-installation than to our everyday experience of being in time.

The doubling of the past (of the past in the present and the present in the past) is multiplied by a mirror covering the wall opposite of the camera and monitor. The mirror reflects whatever is in the room, which includes the image on the monitor. Consequently, when the monitor projects the moment of eight seconds ago, it includes an image of the monitor that was then reflected in the mirror, projecting the moment of 16 seconds ago. The effect is a potentially infinite regress of "time continuums within time continuums."(13) It is therefore not only the past of the present, the memory formed contemporaneously with perception, that coexists with the present; but the past of every present; that is, every present that has past before the camera. Each new present, appearing on the screen, doubles and replays all the others differently, the difference being marked by the interval.

This recalls Bergson's analyses even more. Beginning with the idea that each past is contemporaneous with its present, or more generally, with the idea that time is a continuum, a durational flow, Bergson is led to argue that the whole of the past coexists with the present. The "coiling up" of the past upon the past is incessant; and everything that we have ever lived through (thought, felt, and wanted) is there at every 
moment, "pressing against the portals of consciousness." ${ }^{(14)}$ Bergson asks rhetorically: "what, in fact, are we, what is our character [which becomes visible in each, even the most insignificant gesture, he reminds us elsewhere] if not the condensation of the history that we have lived through since our childhood?" (7-8)

For Bergson the past as a whole coexists with the present; that is to say, the past forms a "whole," in which the multiple moments of an individual's life, but also of life as a whole, are brought together. ${ }^{(15)}$ Paradoxically, however, the unity of the whole is predicated on difference and division. The multiple moments; in the context of the installation: the images of the past on the monitor screen; remain heterogeneous by virtue of the interval of time. They coexist and form a whole only in the sense that they are not discrete instants, but each is affected and transformed in relation to every other.

In other words, the Bergsonian whole is composed of heterogeneous durations, each of which repeats and differentiates all the others. The whole is therefore infinitely open, and signifies the fact that the splitting of the present has no end. It has no end, that is to say, it is unlimited, because there are "time continuums within time continuums," a circuit within every circuit, a repetition within every repetition, a mask (a double) behind every mask. The forking of time into past and present (at the same time) extends infinitely in both directions. Deleuze is right to identify the Bergsonian notion of the past, the past which doubles the present, with the notion of the mise-en-abîme: "The putting into abyss does not redouble the unit, as an external reflection might do; in so far as it is an internal mirroring, it can only ever split it in two,' and subject it to the infinite re-launch of endlessly new splitting." (16) The mise-en-abime of the present in the mirror of the past is what Graham's images effectively perform.

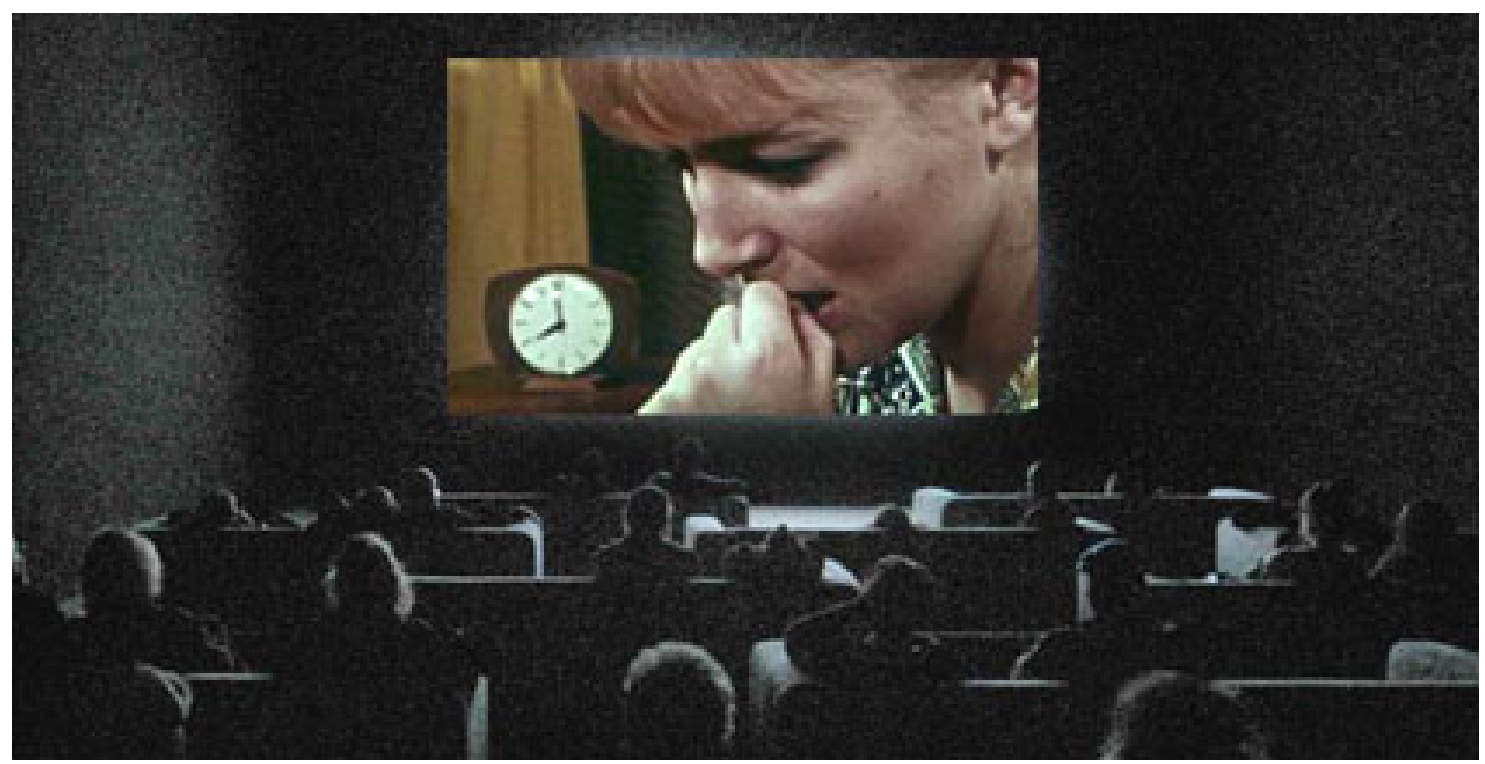

Figure 1: Christian Marclay The Clock

In contrast, on the other side of the screen we see the real-time of the present. It is indexed in the work by a mirror that stands at right angles to the other mirror-wall and to the monitor-wall. Graham writes: "The mirror at right angles to the other mirror-wall and to the monitor-wall gives a present-time view of the installation as if observed from an 'objective' vantage exterior to the viewer's subjective experience and to the mechanism that produces the piece's perceptual effect. It simply reflects (statically) present time."(17) The objective present reflects itself; that is, it is identical to itself. It is, in this sense, homogenous, static, and changeless. However, Graham's work also testifies to the Bergsonian lesson that despite its homogeneity (or because of it) the objective present lacks consistency. The present, Bergson taught and Graham makes us see, can only be preserved by way of an agency - memory - which makes it pass. ${ }^{(18)}$ In other words, only that which displaces and transforms the present is able to constitute its memory; just as it is the time that divides the subject which alone constitutes its unity.

We can always see the video, or any film for that matter, from the standpoint of real-time, by treating the 
images as so many discrete measurable instants. But we would then miss the "perceptual effect" that lies at the heart of the experience of Graham's work. The effect is created in between the images, in and through their relations; or in between the medium and the present of real-time, in and through the medium's relation to time. Similarly, we can represent our own experience of time through the grid-like frame of real-time; but we would neglect the complex and multiple layering of experience that takes place along side of real-time, where past and present communicate, each changing in relation to the other. Graham's work seizes upon and realizes the possibility of this other time, which passes along with real-time.

If we do represent our own experience in terms of real-time, we see ourselves as remaining identical, despite the various changes, across time. For the notion of a unified subject is the correlate of the objective present. But if Graham's work implies a theory of the subject, which surely it does, the theory casts doubt on the presupposition of such a subject. Like much of modern philosophy (after Bergson) the work shows how the subject is constituted in time. The sense of self presupposes the sense of being present to oneself from one moment to the next as the same. It thus presupposes the unity of the present. But the unity of the present depends upon memory, which sustains the present only by dividing it and making it pass. The present cannot therefore be the ground of identity. It is constituted as a divided present; and the subject is constituted as a divided subject. We see this in the video very clearly: the subject is displaced at the very moment that it recognizes itself, the moment of the reflection of (self) perception in its corresponding memory image. Recognition (self-recognition) becomes the locus of mis-recognition (méconnaissance), and of an infinite splitting of the self.

Is Present Continuous Past(s) cinema? The work does use the technology of the moving-image; specifically, it exploits the gap between the time registered (by the camera) and the time projected, which lies at the heart of the apparatus of cinema. On the other hand, one could argue that being placed in the context of an installation, where the viewer's presence before the camera becomes an integral part of the work, this technology serves a different kind of art. Inviting the viewer into the work, making her a participant in the creation of the work and enabling her being present in the work with the help of the technology of the moving image or theatre, is more of a feature of performance art than cinema. The answer to this question, however, depends on what we think the cinema is or can be.

I have taken Stanley Cavell's concept of the screen as a barrier as one of the starting points for this discussion. Graham's work would fall outside of the concept of cinema that I have introduced if it eradicated this barrier; that is, if it allowed the viewer to be present in, to share the same present as, the image screened; if it allowed her sense of presence to be reflected on the screen. For what this barrier signifies is that the cinematographic image is never in the present. ${ }^{(19)}$ The barrier marks the heterogeneity of the time of the screen to the present time of the subject. Graham's work exploits the barrier, that is, the duality of the screen, to create a time in which the unity of the present and the subjective certitude that rests on it are displaced. The work projects an image of the past that remains heterogeneous to the subject.

The fact that the two times become simultaneous, in a mirror relation, allows the subject to see its own time reflected as if it were the time of an other. To put it differently, a past that divides the present from itself is made present or takes the place of the present; just as an otherness that deprives the subject of identity appears in its place, as its double. In The Time-Image Deleuze writes that what we have learned from Kant, and what Bergson made all the more explicit, is that "time is not the interior in us, but just the opposite, the interiority in which we move, live and change;" it is the cinema, he adds, that shows "how we move in it, in this form which carries us away, picks us up and enlarges us" (82). From this point of view, Present Continuous Past(s) is an exemplary instance of cinema. It reveals precisely where the cinema begins (its limit, as it were) to take hold of, divide, and open the subject to the exteriority of a heterogeneous time. ${ }^{(20)}$

One can also question whether The Clock is cinema per se. One could call it a form of performance art, because it engages the present of the spectators, or the spectators present; and because it seems to happen in the present. However, both works make visible the difference between the time that the medium brings into play and that of the present subject; between the time of the screen, in Cavell's words, and that from which it is screened. Whereas real-time is governed by the principle of identity, each now resembling itself and resembling all the others at the same time; the time of the screen is heterogeneous, each moment differing in itself in relation to all the others. It is the medium that creates this heterogeneous time, by bringing time 
into a new relation with itself. In other words, the time that is produced in between the time registered on film and real-time is the time of the cinema. It cannot be traced back to a real (time) referent in the world.

Creating time, creating multiple, heterogeneous times, is a possibility that belongs to the medium of cinema. However, it is not given to it, ready-made, as a universal structure. It is a possibility that must be created, and realized differently, each time. There are many different ways in which the cinema can disarticulate, disassemble, or derange time. Most often film time is created through montage. It emerges through the relations between images, as they unfold from the beginning to the end of the film. The Clock and Present Continuous Past(s) are unique in exploiting the gap between the time registered and the time projected. Each exploits the creative possibility of this gap in its own singular way; turning the present toward the past, as toward a source of the new.

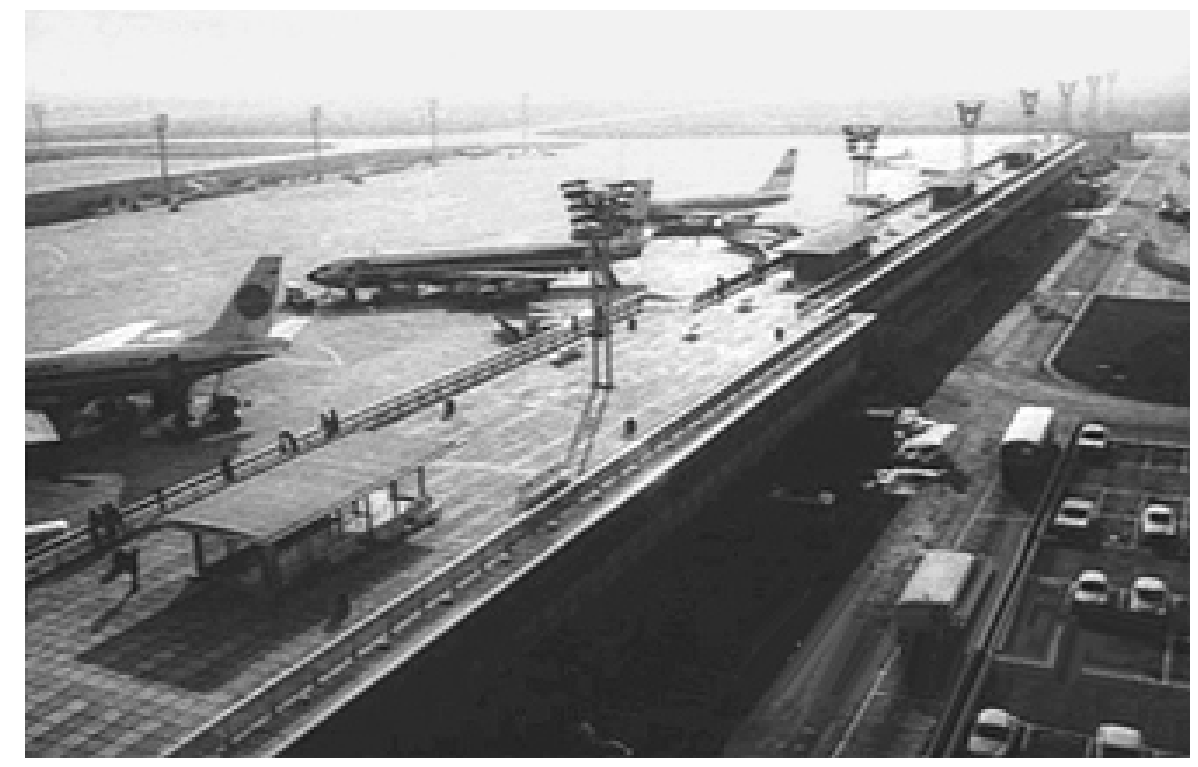

Figure 2: An icon of film time: The jetty in Chris Marker's La jetée

\section{Notes}

1. Henri Bergson, Time and Free Will, trans. F. L. Pogson (Dover Publications, INC., 2001).

2. Bergson writes that in the experience of memory, the subject does not, in recalling former states, "set them alongside its actual state as one point alongside another, but forms both the past and the present states into an organic whole, as happens when we recall the notes of a tune, melting, so to speak, into one another." Time and Free Will, 100.

3. Henri Bergson, Creative Evolution, trans. Arthur Mitchell (The Modern Library, Random House Inc., 1944), 330-333. Bergson saw in the cinema a perfect example of homogeneous time, or of the intellectual mechanism that reduces the diversity of experience to homogeneous time. "The mechanism of our ordinary knowledge is of a cinematographic kind..." (332).

4. Gilles Deleuze, Cinema 1, The Movement-Image, trans. Hugh Tomlinson and Barbara Habberjam (University of Minnesota Press, 1986). Deleuze's two volume study of the cinema begins by arguing against Bergson's claim that the cinema is doomed to reproduce homogeneous ("spatialised") time.

5. "What happens to reality when it is projected and screened?" Stanley Cavell, The World Viewed (Harvard 
University Press, 1979), 16.

6. Cavell writes: "In a movie house, the barrier to the stars is time" (155).

7. David Velasco, "Borrowed Time," Artforum, February 2011.

8. Gilles Deleuze, Cinema 2: The Time-Image, trans. Hugh Tomlinson and Robert Galeta (University of Minnesota Press, 1989).

9. Lucien Logette makes this comparison in his September 2011 review of the film for La Quinzaine littéraire.

10. A detailed description of the work, including a sketch:

http://www.medienkunstnetz.de/works/present-continuous-pasts/ (Accessed 10 January 2011)

11. Elie During, "Le Souvenir du Present," in Faux raccords: La coexistence des images (Actes Sud / Villa Arson, 2010). This chapter has deeply informed my reading of Graham's work.

12. Henri Bergson, "Memory of the Present and False Recognition," in Henri Bergson, Key Writings, ed. K. A. Pearson and John Mullarkey (Continuum, 2002), 144.

13. This is how Dan Graham describes the effect in his artist's statement: http://www.medienkunstnetz.de/works/present-continuous-pasts/ (Accessed 10 January 2011)

14. Henri Bergson, Creative Evolution, 7.

15. The extension of the theory of duration from a theory of the subject to the problem of the unity of life as a whole is made in Creative Evolution. It raises problems that fall outside of the purview of this paper, since Graham's video installation is concerned with the unity of the subject in time. Nonetheless, it should become apparent that the theory of the subject's existence in time already anticipates the later move, insofar as it defines that existence as open towards an event that exceeds it.

16. Gilles Deleuze, Cinema 2: The Time-Image, 82.

17. http://www.medienkunstnetz.de/works/present-continuous-pasts/

18. Henri Bergson, Matter and Memory, trans. N.M. Paul and W. S. Palmer (London: George Allen and Unwin Ltd, 1962), 170-232.

19. Except perhaps in very bad films, as Godard would say; that is, except in films that do not explore the creative possibilities of the time of the medium.

20. Elie During is keen to point out the difference between Graham's work and the performance art tradition. Whereas the latter often aims at creating a sense of presence, that is, of the subject (viewer or artist) being present in the event of the work; Graham's piece serves to displace that sense in favour of revealing the pre-subjective process that constitutes the present in the first place: "Car la question n'est pas de saisir le 'pur présent' de l'acte ou de la performance mais de se rendre attentif au présent qui se fait, et qui souvent aussi se défait. Il ne s'agit pas de chercher la présence dans le processus mais de rendre tangible le processus même du présent: le présent se faisant...; le présent s'exfoliant à mesure qu'il passe."(88)

\section{References}

\section{Bibliography}

Baross, Zsuzsa. "Toward a Memory of the Future: Cinema, Memory, History." In Posthumously: For Jacques Derrida. Sussex Academic Press, 2011.

$5-14$.

"The Future of the Past: The Cinema." Angelaki: Journal of Theoretical Humanities 11.1 (2006):

Bergson, Henri. Creative Evolution. Translated by Arthur Mitchell. The Modern Library: Random House Inc., 1944. 
. Matter and Memory. Translated by N. M. Paul and W. S. Palmer. London: George Allen and Unwin Ltd, 1962.

. "Memory of the Present and False Recognition." In Henri Bergson, Key Writings, edited by K. A. Pearson and John Mullarkey, 141-156. Continuum, 2002.

. Time and Free Will. Translated by F. L. Pogson. Dover Publications, INC., 2001.

Cavell, Stanley. "Sights and Sounds," "Photograph and Screen." In The World Viewed. Harvard University Press, 1979.

Deleuze, Gilles. Cinema 1: The Movement-Image. Translated by Hugh Tomlinson and Barbara Haberjam. Minneapolis: University of Minnesota Press, 1986.

Cinema 2: The Time-Image. Translated by Hugh Tomlinson and Robert Galeta. Minneapolis: University of Minnesota Press, 1989.

During, Elie. "Le Souvenir du Present." In Faux raccords: La coexistence des images. Actes Sud / Villa Arson, 2010

Logette, Lucien. "Pour un OUvroir de CInématographie POtentielle." La Quinzaine littéraire, September 2011.

Media Art Net. "Dan Graham: Present Continuous Past(s). Accessed on 10 January 2011. http://www.medienkunstnetz.de/works/present-continuous-pasts/

Velasco, David. "Borrowed Time," Artforum, February 2011.

\section{Author Information}

Jacob POTEMPSKI is in the third year of the Cultural Studies PhD programme at Trent University. He received his M.A. from the Amsterdam School for Cultural Analysis (University of Amsterdam). His research focuses on questions of temporality and (avant-garde) cinema. 